\title{
a Upconversion fluorescent carbon nanodots enriched with nitrogen for light harvesting $\dagger$
}

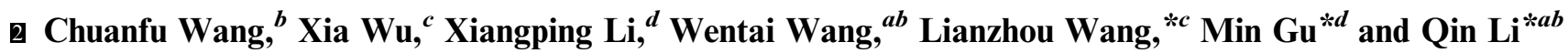

Received 15th February 2012, Accepted 18th June 2012

DOI: $10.1039 / \mathrm{c} 2 \mathrm{jm} 30935 \mathrm{a}$

\begin{abstract}
Fluorescent nitrogen-enriched carbon nanodots (C-dots) of 1 to $3 \mathrm{~nm}$ were obtained through a one-pot reaction between melamine and glycerol. These C-dots show quantum yields up to $22 \%$ and a high two-photon absorption cross-section. $\mathrm{The}^{\mathrm{TiO}_{2}}$ based photoanode sensitized by these $\mathrm{C}$-dots is capable of converting near IR photon energy to photocurrent.
\end{abstract}

The emergence of photoluminescent nanocarbons has attracted significant research interest in recent years, because carbon is cheap, abundant, chemically inert and biocompatible. Carbon nanodots (C-dots) are quasi-spherical particles of finite size, typically less than $5 \mathrm{~nm}$, and comprise either amorphous or graphitic carbon. ${ }^{1-3}$ Various works have demonstrated a promising application potential of C-dots in bioimaging, ${ }^{2,4-7}$ optoelectronic devices ${ }^{8}$ and photocatalysis. ${ }^{9}$

A number of methods have been established to synthesize carbon nanodots, from 'top-down' approaches such as arc-discharge, ${ }^{3}$ laser ablation, ${ }^{2}$ and electrochemical exfoliation ${ }^{10}$ to 'bottom-up' syntheses like carrier-supported resol carbonization, ${ }^{6}$ dehydration of carbohydrates, ${ }^{11}$ thermal oxidation, ${ }^{12}$ microwaving ${ }^{13}$ and 'hot injection' ${ }^{14}$ of carbon precursors. The quantum yields (QYs) of these synthesized C-dots are generally low (typically under 15\%)., ${ }^{2,6,13,15-19}$ While improving synthesis methods towards potential cost-effective mass production is a heated area, various studies have also attempted to unravel the photoluminescence mechanisms of C-dots. The luminescence origin was attributed to a surface trapping effect, ${ }^{2}$ and other

${ }^{a}$ Dept. of Chemical Engineering, Curtin University, GPO Box U1987, Perth,WA 6845, Australia. E-mail: q.li@curtin.edu.au; Fax: +6189266 2581; Tel: +61892667704

${ }^{b}$ Environmental Engineering \& Queensland Micro- and Nanotechnology Centre, Griffith University, QLD4111, Australia.E-mail: qin.li@griffith. edu.au; Fax: +6173735 5198; Tel: +61737357514

'School of Chemical Engineering, The University of Queensland, Brisbane, QLD 4072, Australia. E-mail: l.wang@uq.edu.au; Fax: +61 7 33654199; Tel: +61733654218

${ }^{d}$ Centre for Micro-Photonics, Faculty of Engineering and Industrial Sciences, Swinburne University of Technology, Hawthorn, VIC 3122, Australia.E-mail: mgu@swin.edu.au; Fax: +61 39214 5435; Tel: +61 3 92145273

$\dagger$ Electronic supplementary information (ESI) available: Experiment details, quantum yield determination, photos of C-dots, optical spectra of C-dots prepared when citric acid was substituted by HZSM-5 or $\mathrm{H}_{2} \mathrm{SO}_{4}, 2 \mathrm{P}$ cross-section, FTIR and XPS spectra, as well as data on solar cell tests including a comparative study with non-N-rich C-dots, and photocurrent versus light intensity. See DOI: 10.1039/c2jm30935a studies suggested that it is the graphene fragments within the $\mathrm{sp}^{3}$ carbon matrix that are responsible for the HOMO-LUMO gap. ${ }^{20}$ While the exact mechanisms remain elusive, we cannot exclude the possibility that there may be multiple mechanisms at work and the dominant mechanism in the various reported C-dots may differ due to their structural differences as a result of different synthesis methods. The understanding may be gained through further comparative studies.

In this study, for the first time we have explored heteroatom doping into the carbon structure and its effects on the optical properties. Herewith we present a simple one-pot synthesis of nitrogenrich fluorescent $\mathrm{C}$-dots as well as its reaction mechanisms. In this study melamine was employed as the co-precursor along with glycerol for forming fluorescent nanoparticles. Melamine, due to its richness of nitrogen content, has long been recognised as an excellent precursor to form $\mathrm{N}$-doped carbon materials for enhancing catalytic activities. ${ }^{21}$ The QY of the nitrogen-rich C-dots is up to $22 \%$, which is the highest QY for hydrophilic C-dots from one-pot synthesis, to the best of our knowledge. Moreover, the $\mathrm{N}$-rich $\mathrm{C}$-dots possess a larger two-photon (2P) cross-section than their counterparts without nitrogen. We also demonstrate for the first time the application of $\mathrm{C}$-dots as a light harvesting agent for $\mathrm{TiO}_{2}$-based solar cells.

The nitrogen-rich C-dots were synthesized by reacting melamine with glycerol at an elevated temperature in the presence of an acid catalyst, such as citric acid, or $\mathrm{H}_{2} \mathrm{SO}_{4}$ or $\mathrm{H}-\mathrm{ZSM}-5$. In a typical experiment, $0.5 \mathrm{~g}$ of melamine was first dispersed in $18 \mathrm{ml}$ of glycerol. The mixture was heated to $270^{\circ} \mathrm{C}$ under nitrogen flow, and $0.5 \mathrm{~g}$ of citric acid was quickly added to the hot mixture, where citric acid can be replaced by a drop of $98 \% \mathrm{H}_{2} \mathrm{SO}_{4}$ or $0.1 \mathrm{~g}$ of H-ZSM-5. The mixture was maintained at $270{ }^{\circ} \mathrm{C}$ for $15 \mathrm{~min}$ and then cooled to ambient temperature, resulting in a dark brown viscous mixture. The mixture is highly soluble in water and emits strong blue fluorescence under a UV lamp (Fig. S2 in the ESI $\dagger$ ).

The AFM and TEM images (Fig. 1) show that most particles range from $0.8 \mathrm{~nm}$ to $1.5 \mathrm{~nm}$ in size, with few particles up to $3 \mathrm{~nm}$. Through dialysis by membranes with MWCO (molecular weight cutoff) 3500 and MWCO 1000, three fractions of C-dots were obtained, namely greater than $3.5 \mathrm{k}$, between $1 \mathrm{k}$ and $3.5 \mathrm{k}$, and smaller than $1 \mathrm{k}$. They are referred to as $3.5 \mathrm{k}, 1 \mathrm{k}$ and $<1 \mathrm{k}$ respectively.

A close inspection of their UV-vis absorption spectra in Fig. $2 \mathrm{a}-\mathrm{c}$ shows that all three fractions of nanoparticles exhibit strong optical absorption in the UV region with an exponential decay curve extending into the visible range, similar to previous reports on C-dots. 

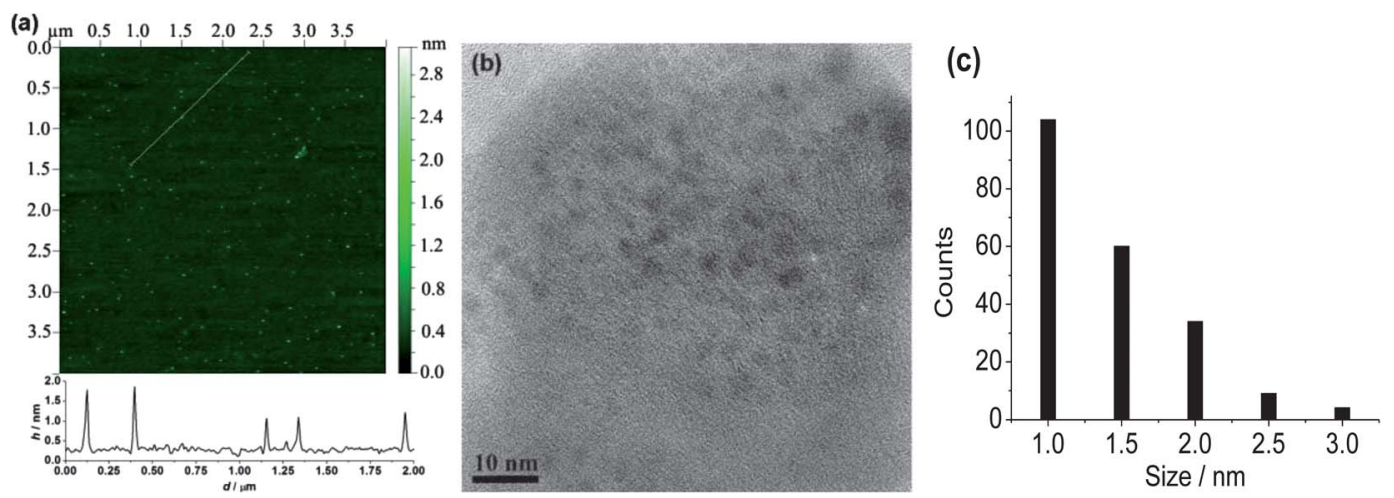

Fig. 1 AFM (a) and TEM (b) images and size distribution from AFM images (c) of as prepared C-dots.
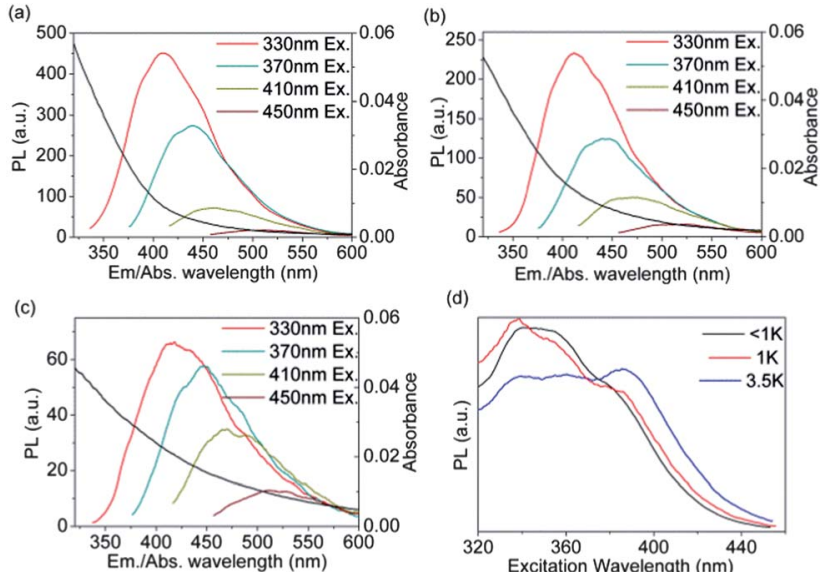

(d)

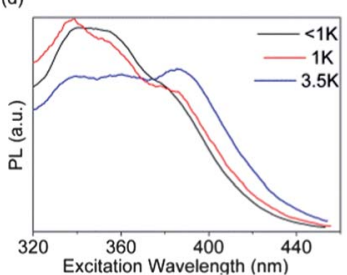

Fig. 2 UV-vis absorption and PL emission spectra of $<1 \mathrm{k}(\mathrm{a}), 1 \mathrm{k}$ (b) and $3.5 \mathrm{k}$ (c) with $330 \mathrm{~nm}, 370 \mathrm{~nm}, 410$ and $450 \mathrm{~nm}$ excitation, respectively; (d) excitation spectra of emission $450 \mathrm{~nm}$.

However, it is discernible that as the particle size enlarges, the absorption in the UV region decreases accompanied by increased absorption in the visible range. The photoluminescence (PL) emission spectra of the three fractions (Fig. 2a-c) show that they are all multicolored, where the emission maxima shift bathochromically as the excitation wavelength increases from $330 \mathrm{~nm}$ to $600 \mathrm{~nm}$ in a stepwise manner, as reported previously. ${ }^{1-3,15}$ While fractions $<1 \mathrm{k}$ and $1 \mathrm{k}$ have a similar emission pattern, the $3.5 \mathrm{k}$ fraction shows much weaker PL under short wavelength excitation and relatively increased PL intensity under long wavelengths. This suggests that there may exist dual or multiple emission centers, and the larger C-dots (3.5k) are more susceptible to long wavelength emission.

The PL excitation spectra at emission $450 \mathrm{~nm}$ (Fig. 2d) confirm the existence of multiple emitting centres. The PL excitation band of $<1 \mathrm{k}$ presents a broad peak ranging from $330-360 \mathrm{~nm}$, whilst the excitation spectrum of $1 \mathrm{k}$ shows a distinct peak at $330 \mathrm{~nm}$ and a discernible shoulder at $380 \mathrm{~nm}$, and $3.5 \mathrm{k}$ has broad absorption from 330 to 400 $\mathrm{nm}$ with a small peak around $386 \mathrm{~nm}$. The PL emission and excitation spectra suggest that there are different fluorophore centers when the nanoparticle size varies. The QYs of the three fractions also differ significantly, namely $22 \%, 10 \%$ and $5 \%$ for $<1 \mathrm{k}, 1 \mathrm{k}$ and $3.5 \mathrm{k}$, respectively. The size-dependent fluorescence of $\mathrm{N}$-rich $\mathrm{C}$-dots is somewhat consistent with previous observation, ${ }^{15}$ however, it does

not exclude other possible influencing factors, such as functional groups on the surface or the polyaromatic fluorophores within the carbogenic core. ${ }^{22}$ It should be appreciated that when melamine is not introduced in the synthesis system, the QY of the resulting nanoparticles is noticeably lower, at about $10 \%$.

FTIR and XPS analyses were carried out to provide insight into the chemical structure of these N-rich C-dots. A comparison of the FTIR spectra of the precursors and N-rich C-dots as shown in Fig. S4 in the ESI $\uparrow$ highlights the co-existence of the triazine structure (fingerprints between $1400 \mathrm{~cm}^{-1}$ and $1600 \mathrm{~cm}^{-1}$ ) derived from melamine and the hydroxyl groups (peak centered at $3300 \mathrm{~cm}^{-1}$ ) and the aliphatic chain (peaks at $2880 \mathrm{~cm}^{-1}$ and $2930 \mathrm{~cm}^{-1}$ ) from glycerol. The vibrational fingerprint of $-\mathrm{CH}=\mathrm{O}$ centered at $1750 \mathrm{~cm}^{-1}$ suggests that some of the hydroxyl groups have been converted into aldehyde groups. Overall, the FTIR spectra indicate that the obtained nanodots are a product of the reaction between melamine and glycerol and in a form between the polymer and carbon. A parallel experiment without citric acid also resulted in fluorescent species, but with much lower QY, about 8\%. Moreover, when citric acid is replaced by concentrated $\mathrm{H}_{2} \mathrm{SO}_{4}$ or a solid acid such as H-ZSM-5 zeolite, carbonaceous nanoparticles with QY $17 \%$ were also obtained, confirming the catalytic role of citric acid in this dehydration and condensation reaction.

A full spectra XPS analysis provides the calibrated atom ratio of $\mathrm{O}: \mathrm{N}: \mathrm{C}$ as of $3.2: 1: 6$ for the $1 \mathrm{k}$ fraction and $2.7: 1: 8$ for $3.5 \mathrm{k}$. The higher oxygen content accompanied with lower carbon percentage of fraction $1 \mathrm{k}$ compared to $3.5 \mathrm{k}$ suggests that the $3.5 \mathrm{k}$ fraction has undergone further dehydration and condensation. $\mathrm{C} 1 \mathrm{~s}$ analysis (ESI Fig. S5 and Table $1 \dagger$ ) reveals the existence of $\mathrm{C}-\mathrm{C}$ $(284.1 \mathrm{eV}), \mathrm{C}-\mathrm{N}(284.5 \mathrm{eV}), \mathrm{C}-\mathrm{O}(285.5 \mathrm{eV})$ and $\mathrm{C}=\mathrm{N}(287.7 \mathrm{eV})$ bonds in both samples. Quantitative comparison of the bonds shows that the $3.5 \mathrm{k}$ contains more triazine rings derived from melamine. Taken together, these analyses suggest that the size-dependent optical properties may be related to the size of the poly-heterocyclic ring structure in the nanoparticles. ${ }^{20}$

It is also observed that this heteroatom doped C-dot has enlarged multi-photon upconversion fluorescence. Its two-photon (2P) crosssection is measured to be about $1320 \mathrm{GM}\left(1 \mathrm{GM}=10^{-50} \mathrm{~cm}^{4} \mathrm{~s}\right.$ photon $^{-1}$ ) when excited by a pulsed laser at the wavelength of $720 \mathrm{~nm}$, which is considerably larger than what has been reported on CdSe quantum dots of similar sizes. ${ }^{23}$ Compared to the C-dots prepared without introducing nitrogen as the heteroatom, ${ }^{14} \mathrm{~N}$-rich $\mathrm{C}$-dots show a much enlarged $2 \mathrm{P}$ cross-section. This may be 

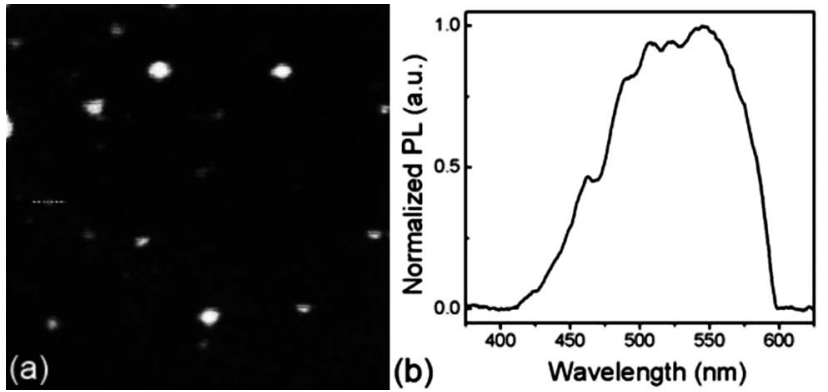

Fig. 3 (a) Two-photon imaging of N-rich C-dots ( 20 micron by 20 micron). (b) The two-photon fluorescence spectrum of a single N-rich $\mathrm{C}$-dot indicated by the dashed line in (a) excited at the wavelength of $720 \mathrm{~nm}$.

attributed to the increased intramolecular electron-transfer as a result of $\mathrm{N}$ doping in the cyclic structure. ${ }^{24} \mathrm{It}$ is worth noting that, when tested alone, the $3.5 \mathrm{k}$ fraction is shown to possess the highest $2 \mathrm{P}$ cross-section, reaching $2000 \mathrm{GM}$. The nanodots are clearly visible by $2 \mathrm{P}$ imaging as shown in Fig. 3, demonstrating strong potential for $2 \mathrm{P}$ single molecule imaging.

Inspired by its enlarged multi-photon upconversion fluorescence, we tested the application of using $\mathrm{N}$-rich $\mathrm{C}$-dots as a replacement for organic dyes in dye-sensitised solar cells, particularly for harvesting near infrared (NIR) photoenergy. Standard Dyesol ${ }^{\mathrm{TM}} \mathrm{TiO}_{2}$-coated test cell glass plates (with TEC 15 FTO and $18 \mathrm{NR}-\mathrm{T} \mathrm{TiO}_{2}$ coating layer) were employed and loaded with $\mathrm{C}$-dots by soaking overnight. Under simulated solar irradiation (AM 1.5, $100 \mathrm{~mW} \mathrm{~cm}^{-2}$ ), the opencircuit voltage $\left(V_{\mathrm{oc}}\right)$ reached $565 \mathrm{mV}$, with a photocurrent density $\left(J_{\mathrm{sc}}\right)$ of $0.8 \mathrm{~mA} \mathrm{~cm} \mathrm{~cm}^{-2}$ and a fill factor of 0.293 and the overall conversion efficiency $(\eta)$ was characterized as $0.13 \%$, which is comparable to CdSe and InAs sensitized solar cells. ${ }^{25,26}$ The low fill factor of the solar cell can be mainly attributed to the relatively high charge recombination rate with the $\mathrm{C}$-dot sensitization. The incident photon-to-current conversion efficiency (IPCE) spectra of solar cells based on a C-dot sensitized $\mathrm{TiO}_{2}$ film and a blank $\mathrm{TiO}_{2}$ film are shown in Fig. 4. It can be observed that without C-dot sensitization, the IPCE of the blank $\mathrm{TiO}_{2}$ solar cell remained evenly at zero percent in the entire UV-visible light regime, whereas the IPCE of the C-dot sensitized solar cell exhibited a dramatic increase in the UV to visible range owing to the efficient photosensitization by incorporating C-dots. The main peak of $c a .25 .3 \%$ quantum efficiency (QE) at $340 \mathrm{~nm}$ corresponds to the single photon absorption peak of the

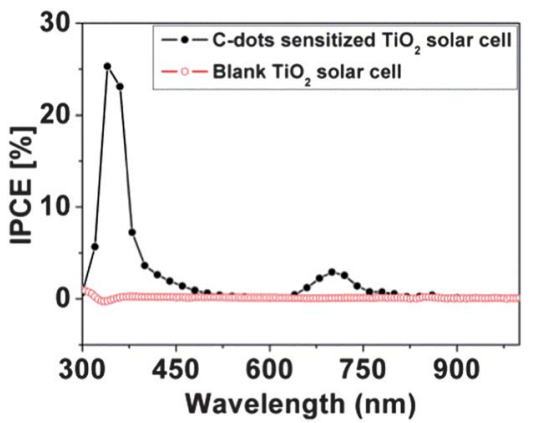

Fig. 4 IPCE spectra of solar cells based on the N-rich C-dot sensitized $\mathrm{TiO}_{2}$ film and the blank $\mathrm{TiO}_{2}$ film.

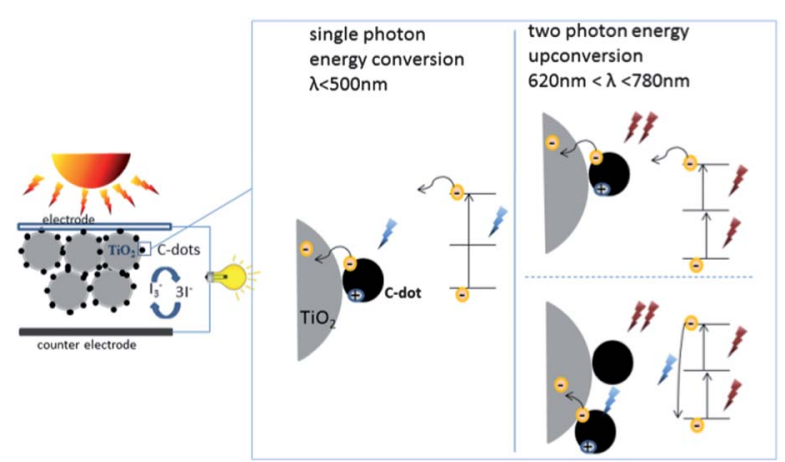

Scheme 1 Working mechanisms of nitrogen-enriched C-dots as light harvesting agents for the $\mathrm{TiO}_{2}$ based photoanode.

C-dots and a smaller peak of $c a .2 .9 \%$ QE appears at $700 \mathrm{~nm}$. One may argue that the strong UV range absorption of $\mathrm{N}$-doped C-dots may compete with the UV absorption of $\mathrm{TiO}_{2}$. However, as contrasted by the IPCE spectrum of a blank Dyesol chip (with $\mathrm{TiO}_{2}$ film alone), it is evident that the $\mathrm{N}$-doped C-dots are significantly more susceptible to charge-hole separation under the UV irradiation, and the excited electrons have been effectively injected into the $\mathrm{TiO}_{2}$ matrix. The rising of the second IPCE peak in the near IR range is attributed to the large two photon cross-sections of the nitrogenated C-dots, which is confirmed by the quadratic dependence of photocurrent on the input intensity (ESI Fig. S7 $\uparrow$ ). The energy conversion mechanisms may involve both charge transfer induced by two photon excitations and upconversion fluorescence, as illustrated in Scheme 1. Overall, the N-rich C-dots have enabled the absorption and conversion of near IR photon energy to electric current, serving as efficient energy harvesting and transfer components. It can also be envisaged that the overall conversion efficiency of the C-dot sensitised solar cell can be significantly improved by modifications on recombination inhibition and electron transfer enhancement.

\section{Conclusions}

In conclusion, we have synthesized nitrogenated carbogenic nanoparticles less than $3 \mathrm{~nm}$ via a facile one-pot route by reacting melamine and glycerol in the presence of an acid catalyst. The nitrogen-containing C-dots are highly fluorescent with QY up to $22 \%$ and can potentially be used for multi-photon single molecule imaging. Samples fractionated according to size show differences in the degree of carbonization, which may be accountable for the variations in fluorescence centres among the size-fractionated samples. The N-rich C-dots were applied to sensitize $\mathrm{TiO}_{2}$ solar cells, showing comparable performance to $\mathrm{CdSe}$ and InAs quantum dots at their early development stage. More significantly, the C-dot sensitized solar cell is responsive under near IR irradiation owing to the energy upconversion ability of the N-rich C-dots. Since IR comprises $53 \%$ of solar energy, $\mathrm{N}$-doped $\mathrm{C}$-dots appear to be a very promising light-harvesting material that can be applied in tandem with other photosensitizers which absorb in the complementary wavelength ranges to achieve higher energy conversion yield.

\section{Acknowledgements}

We thank Dr Thomas Becker at Nanochemistry Research Institute, Curtin University for his help with the AFM. 


\section{Notes and references}

1 S. N. Baker and G. A. Baker, Angew. Chem., Int. Ed., 2010, 49, 67266744.

2 Y. P. Sun, B. Zhou, Y. Lin, W. Wang, K. A. S. Fernando, P. Pathak, M. J. Meziani, B. A. Harruff, X. Wang, H. F. Wang, P. J. G. Luo, H. Yang, M. E. Kose, B. L. Chen, L. M. Veca and S. Y. Xie, J. Am. Chem. Soc., 2006, 128, 7756-7757.

3 X. Y. Xu, R. Ray, Y. L. Gu, H. J. Ploehn, L. Gearheart, K. Raker and W. A. Scrivens, J. Am. Chem. Soc., 2004, 126, 12736-12737.

4 S. T. Yang, X. Wang, H. F. Wang, F. S. Lu, P. J. G. Luo, L. Cao, M. J. Meziani, J. H. Liu, M. Chen, Y. Huang and Y. P. Sun, J. Phys. Chem. C, 2009, 113, 18110-18114.

5 L. Cao, X. Wang, M. J. Meziani, F. S. Lu, H. F. Wang, P. J. G. Luo, Y. Lin, B. A. Harruff, L. M. Veca, D. Murray, S. Y. Xie and Y. P. Sun, J. Am. Chem. Soc., 2007, 129, 11318-11319.

6 R. L. Liu, D. Q. Wu, S. H. Liu, K. Koynov, W. Knoll and Q. Li, Angew. Chem., Int. Ed., 2009, 48, 4598-4601.

7 Q. Li, T. Y. Ohulchanskyy, R. L. Liu, K. Koynov, D. Q. Wu, A. Best, R. Kumar, A. Bonoiu and P. N. Prasad, J. Phys. Chem. C, 2010, 114, $12062-12068$.

8 F. Wang, Z. Xie, H. Zhang, C. Y. Liu and Y. G. Zhang, Adv. Funct. Mater., 2011, 21, 1027-1031.

9 H. T. Li, X. D. He, Z. H. Kang, H. Huang, Y. Liu, J. L. Liu, S. Y. Lian, C. H. A. Tsang, X. B. Yang and S. T. Lee, Angew. Chem., Int. Ed., 2010, 49, 4430-4434.

10 Q.-L. Zhao, Z.-L. Zhang, B.-H. Huang, J. Peng, M. Zhang and D.-W. Pang, Chem. Commun., 2008, 5116-5118.

11 H. Peng and J. Travas-Sejdic, Chem. Mater., 2009, 21, 5563-5565.
12 A. B. Bourlinos, A. Stassinopoulos, D. Anglos, R. Zboril, V. Georgakilas and E. P. Giannelis, Chem. Mater., 2008, 20, 4539-4541.

13 H. Zhu, X. L. Wang, Y. L. Li, Z. J. Wang, F. Yang and X. R. Yang, Chem. Commun., 2009, 5118-5120.

14 F. Wang, S. P. Pang, L. Wang, Q. Li, M. Kreiter and C. Y. Liu, Chem. Mater., 2010, 22, 4528-4530.

15 H. P. Liu, T. Ye and C. D. Mao, Angew. Chem., Int. Ed., 2007, 46, 6473-6475.

16 L. Tian, D. Ghosh, W. Chen, S. Pradhan, X. J. Chang and S. W. Chen, Chem. Mater., 2009, 21, 2803-2809.

17 Q. L. Zhao, Z. L. Zhang, B. H. Huang, J. Peng, M. Zhang and D. W. Pang, Chem. Commun., 2008, 5116-5118.

18 J. Lu, J. X. Yang, J. Z. Wang, A. L. Lim, S. Wang and K. P. Loh, ACS Nano, 2009, 3, 2367-2375.

19 B. Zhang, C. Y. Liu and Y. Liu, Eur. J. Inorg. Chem., 2010, 4411-4414.

20 G. Eda, Y. Y. Lin, C. Mattevi, H. Yamaguchi, H. A. Chen, I. S. Chen, C. W. Chen and M. Chhowalla, Adv. Mater., 2010, 22, 505.

21 T. J. Bandosz, Surface Chemistry of Carbon Materials, in Carbon Materials for Catalysis, ed. P. Serp, J. L. Figueiredo, Wiley, 2009.

22 A. B. Bourlinos, A. Stassinopoulos, D. Anglos, R. Zboril, M. Karakassides and E. P. Giannelis, Small, 2008, 4, 455-458.

23 S. C. Pu, M. J. Yang, C. C. Hsu, C. W. Lai, C. C. Hsieh, S. H. Lin, Y. M. Cheng and P. T. Chou, Small, 2006, 2, 1308-1313.

24 G. S. He, L.-S. Tan, Q. Zheng and P. N. Prasad, Chem. Rev., 2008, 108, 1245-1330.

25 A. Salant, M. Shalom, I. Hod, A. Faust, A. Zaban and U. Banin, ACS Nano, 2010, 4, 5962-5968.

26 P. R. Yu, K. Zhu, A. G. Norman, S. Ferrere, A. J. Frank and A. J. Nozik, J. Phys. Chem. B, 2006, 110, 25451-25454. 